\title{
In praise of academic dust-ups
}

When this journal was launched 12 years ago, we hoped that it would include some robust debates about salient issues, with exchanges between contributors that generated useful insights. In the event, this has barely happened.

Indeed, until now the single example was an (invited) exchange in 2011-2012 over the relative merits of randomised controlled trials in children's services. Sarah Stewart-Brown and her colleagues queried their value, Donald Forrester and Gary Ritter critiqued those arguments, and then Stewart-Brown responded to the critique (Stewart-Brown et al., 2011; Forrester, 2012; Ritter, 2012; Stewart-Brown, 2012). Two interesting footnotes to that discussion: a couple of academics admonished us for publishing the original article, arguing that such a perspective should not be given airtime; and when the original article is cited, the responses tend not to be (perhaps the fear of those who ticked us off).

Leaving that (still live) debate aside, it is gratifying to publish an article, by Keith Goldstein and colleagues, in this edition (my final as an Editor) that responds to an earlier article on the value or otherwise for academic results of interventions that seek to enhance parents' involvement in their children's education (See and Gorard, 2015). Without commenting in any way on either of these articles, I hope that the authors of the original one will take the opportunity to reply.

It got me thinking about the nature and value of such debates in our field. Personally I like them. I suspect this is partly the thrill - relatively speaking - of watching an academic dust-up, but also because exposing points of agreement and difference is helpful and may even generate new insights. At a personal level, it is useful to hear other people's perspectives on things that I am interested in, especially when they differ to mine, and I find that engaging with them helps me to sharpen or clarify my own thoughts. Sometimes it makes me change my mind, or gives me ideas for new studies, or helps me to develop my thinking in new and, to me at least, interesting ways.

There are different types of debate, of course, and all have their place: those that are essentially technical, focused on method and the interpretation of results (such as the one in this edition, or the one between Dennis Gorman on the one hand, and Gilbert Botvin, Kenneth Griffin, David Hawkins and Rico Catalano on the other, about trials of substance abuse prevention programmes: Gorman, 2005a, b; Botvin and Griffin, 2005; Hawkins and Catalano, 2005); those that are more philosophical, concerned with epistemological and ontological approaches (notably the spat between Stephen Webb and Brian Sheldon on evidence-based practice in social work: Webb, 2001; Sheldon, 2001); and those that are fundamentally about ideology (evident, in part, in recent critiques of early intervention as a neoliberal enterprise, including the exchange between Brid Featherstone and colleagues and Vashti Berry and yours truly: Featherstone et al., 2014; Axford and Berry, 2017).

None of these types of debate are mutually exclusive, indeed I suspect that often what presents as one type is partially about the others. In a subject area such as domestic violence, for instance, where ideological differences have driven research and led to different findings about cause and treatment, it is difficult for the academics involved to cross the ideological bridge between the feminist and family violence perspectives, regardless of the empirical evidence presented by the other "side".

But if debates in our field are to be more than ill-tempered fisticuffs there are probably some basic rules of exchange that extend beyond basic courtesy and a focus on the work not the people involved. 
The first is surely that, to some degree at least, we need to be open to changing our mind, either by force of argument or by the evidence presented (or both). On some things, perhaps those that are essentially ideological, we might be resolute: I cannot see myself thinking that capital punishment is anything but abhorrent, for example, even if evidence were presented to me showing that it helped to reduce crime. On other types of issue, however, the empirical evidence could, potentially, prompt a change of view. Show me compelling evidence that climate change is not happening, for instance, and I will move camp.

A second seemingly reasonably ground rule is that we represent as fairly as we can the perspective that is at odds with our own. We owe this to ourselves, the people whose work we are critiquing, and, most importantly, the wider academic field. Politicians prove daily how easy - and tempting - it is to paint the "opposition" as scurrilous rogues by exaggerating or underplaying parts of what they have said. The slightest chink of light between two ministers' statements becomes "government in meltdown", and caveats and qualifiers are merrily stripped out to make the most nuanced pronouncements phrases seem bald and - this is the point - offensive or plain wrong. But, in science, who does this help? It is fun to play to the crowd but it generates far more heat than light.

Third, instead of seeking primarily to persuade others of our point of view, it is arguably more helpful in a scientific debate to identify what evidence will help us to know the right answer (or at least achieve consensus). Put another way, what would it take to convince me that my position is wrong? And what evidence would persuade those I disagree with to change their mind? This is not about winning or losing; it is about the pursuit of truth. If we can agree on why we hold certain views - the underlying assumptions and the reasoning that flows from these - and what would cause us to change them, we are more likely to make progress in our collective understanding. Ultimately, this will help to improve the lives of those we seek to help.

A quick search of the last ten years of a handful of other journals in the children's services field indicates that this journal is not alone in publishing few exchanges (there is plenty of lobbing grenades from afar, but comparatively little hand-to-hand combat). Why is this?

Perhaps it is because the stakes are not high enough (lots of competing perspectives can simply co-exist, with little bearing on policy or practice), or because we rarely move outside our particular academic silo (characterised by shared ideological leanings and methodological preferences). Maybe we fear criticism and the assumed embarrassment of being shown to be wrong (an understandable human foible), or our expectations of debate are so low that we lack the necessary supporting structures and development opportunities (the letters page found in many medical journals, for instance, is largely absent from more socially orientated journals, and we tend not to train younger researchers in debating and being open to critique). Further, in some cases commercial interests and personal conflict of interest can make it very difficult to concede that one might be mistaken. Of course, it could also be that we shy away from anything too adversarial (terms like "rebuttal" and "rejoinder" sound rather gladiatorial), or are simply too nice.

Whichever way, I am delighted to be handing the baton over to a great new editorial team, and the future direction and content of this journal are obviously for them to decide. But until then, here's to a few more enlightening academic ding-dongs (in the nicest possible way), whether in these pages or elsewhere.

\section{References}

Axford, N. and Berry, V. (2017), "Perfect bedfellows: why early intervention can play a critical role in protecting children - a response to Featherstone et al. (2014) 'A marriage made in hell: child protection meets early intervention'", British Journal of Social Work, advance access, 18 March.

Botvin, G.J. and Griffin, K.W. (2005), "Prevention science, drug abuse prevention, and life skills training: comments on the state of the science", Journal of Experimental Criminology, Vol. 1 No. 1, pp. 63-78.

Featherstone, B., Morris, K. and White, S. (2014), "A marriage made in hell: early intervention meets child protection", British Journal of Social Work, Vol. 44 No. 7, pp. 1735-49.

PAGE 222 JOURNAL OF CHILDREN'S SERVICES $\mid$ VOL. 12 NO. 42017 
Forrester, D. (2012), "Are the people who take part in randomised controlled trials real? A response to Stewart-Brown et al.”, Journal of Children's Services, Vol. 7 No. 2, pp. 144-7.

Gorman, D.M. (2005a), "Drug and violence prevention: rediscovering the critical rational dimension of evaluation research", Journal of Experimental Criminology, Vol. 1 No. 1, pp. 39-62.

Gorman, D.M. (2005b), "The centrality of critical rational reasoning in science: a response and further comments on the life skills training program, the Seattle Social Development Project, and Prevention Studies", Journal of Experimental Criminology, Vol. 1 No. 2, pp. 263-75.

Hawkins, J.D. and Catalano, R.F. (2005), "Doing prevention science: a response to Dennis M. Gorman and a brief history of the quasi-experimental study nested within the Seattle Social Development Project", Journal of Experimental Criminology, Vol. 1 No. 1, pp. 79-86.

Ritter, G. (2012), "Using the proper tool for the task: RCTs are the gold standard for estimating programme effects - a response to Stewart-Brown et al.", Journal of Children's Services, Vol. 7 No. 2, pp. 148-52.

See, B.H. and Gorard, S. (2015), "Does intervening to enhance parental involvement in education lead to better academic results for children? An extended review", Journal of Children's Services, Vol. 10 No. 3, pp. 252-64.

Sheldon, B. (2001), "The validity of evidence-based practice in social work: a reply to Stephen Webb", British Journal of Social Work, Vol. 31 No. 5, pp. 801-9.

Stewart-Brown, S. (2012), "More thoughts on the RCT question: a rejoinder to Forrester and Ritter", Journal of Children's Services, Vol. 7 No. 2, pp. 153-8.

Stewart-Brown, S., Anthony, R., Wilson, L., Winstanley, S., Stallard, N., Snooks, H. and Simkiss, D. (2011), "Should randomised controlled trials be the 'gold standard' for research on preventive interventions for children?”, Journal of Children's Services, Vol. 6 No. 4, pp. 228-35.

Webb, S.A. (2001), "Some considerations on the validity of evidence-based practice in social work", British Journal of Social Work, Vol. 31 No. 1, pp. 57-79. 